\title{
1. 体育的遊ひと，健康生活の習虽形成を通して幼児健廉增進之人间形成についての実䟻的研究
}

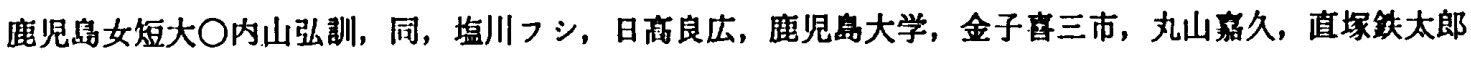

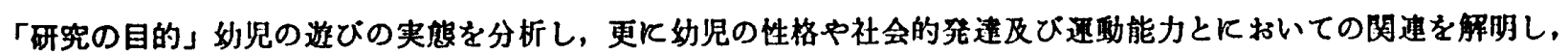
望ましい健康生活の習慣化や体育的遊びの生活化を目ざす。

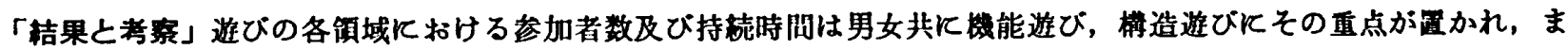

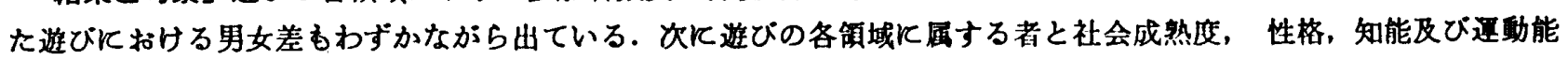

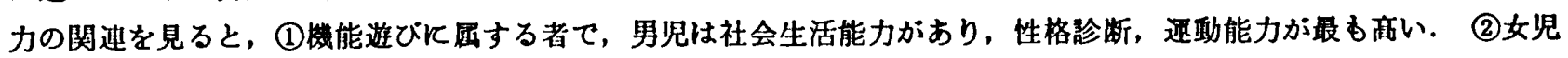

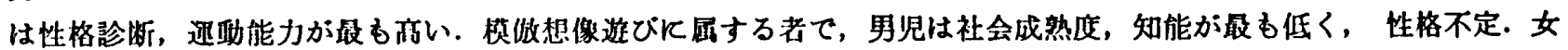

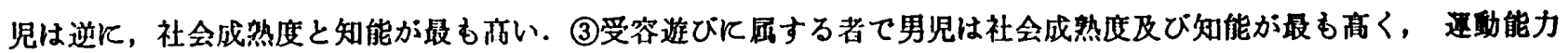

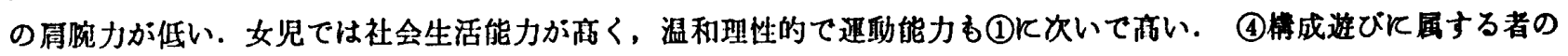

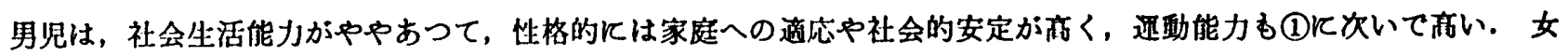

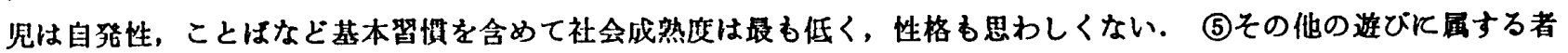

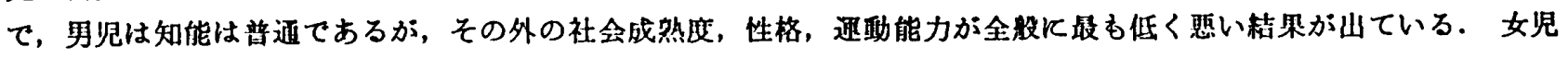
は社会生活能力の一面で良いのもあるが, 性格, 知能, 迅動能力など最も低い。

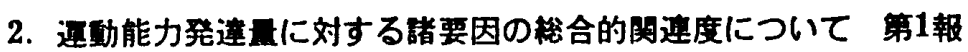

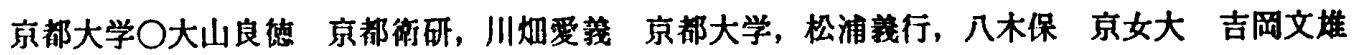

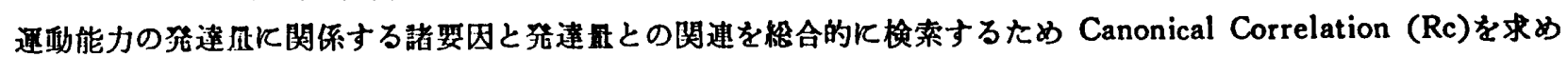

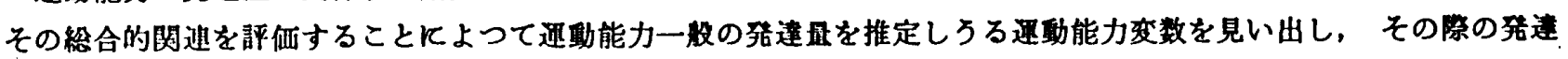

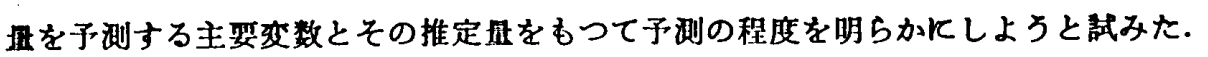

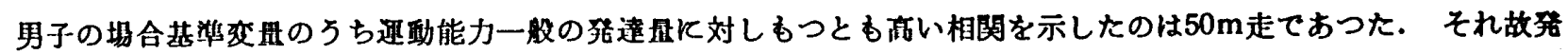

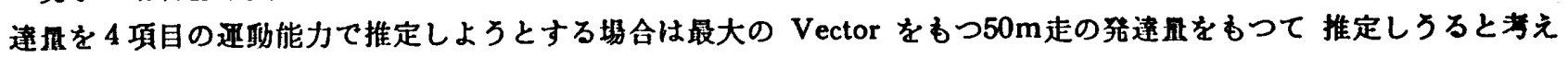

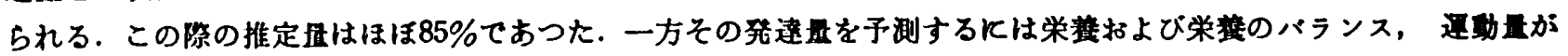

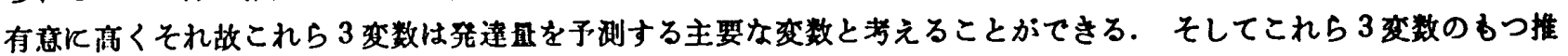

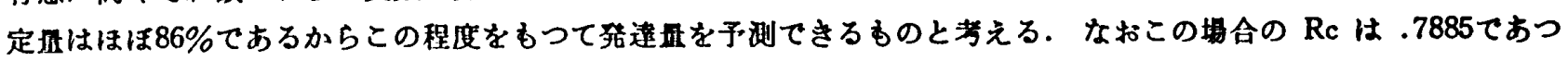

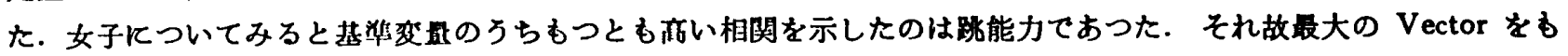

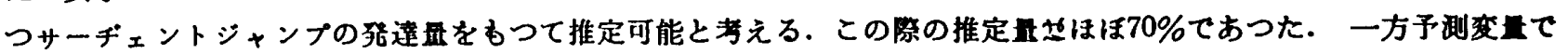

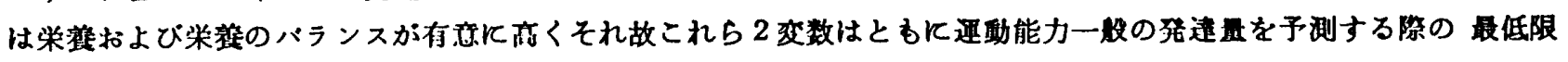

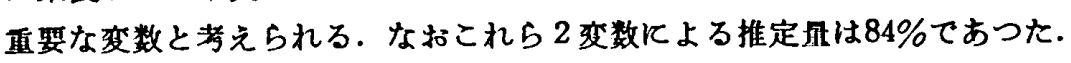

\section{3.「体格及び体力の発育発達に対する遇動要因の関虽」第2報}

京都大学○八木保，松浦義行，大山良德 京都府街生研究所，川㚼爱㖪

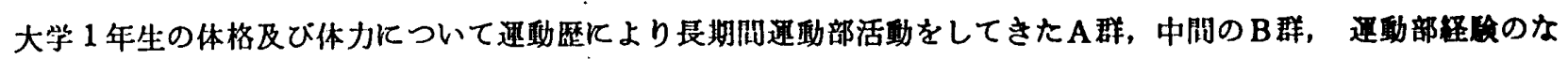

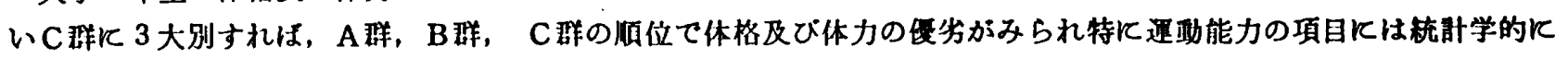

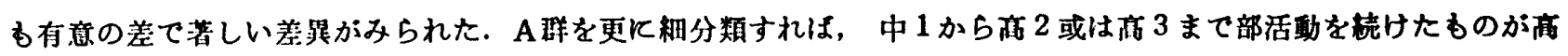

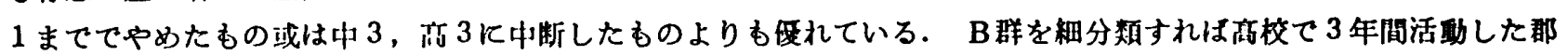

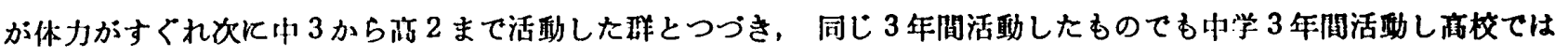

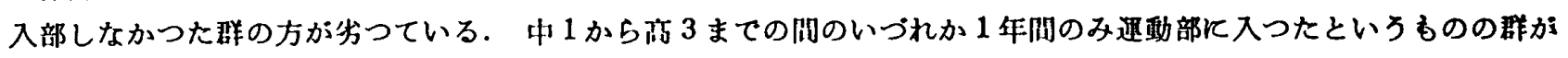

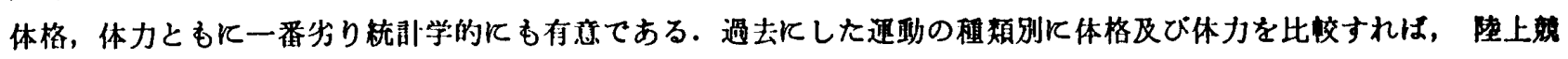

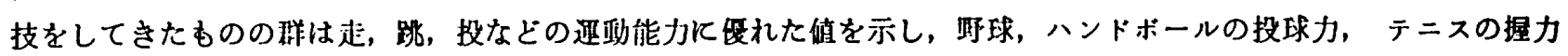

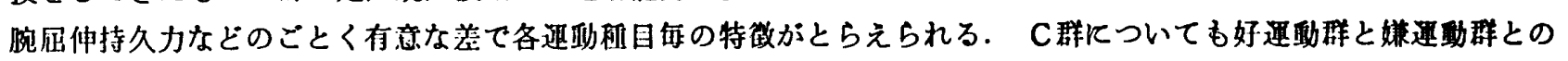
间恃特走跳段, 持久力などの迅動能力有意差がみられる。

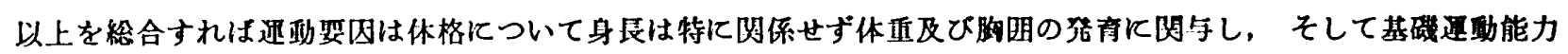

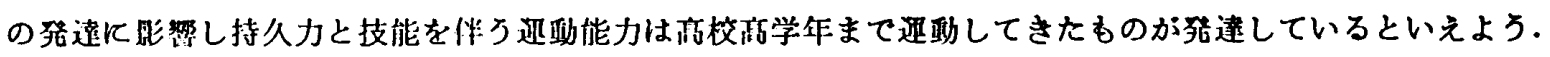

